\title{
Kentsel Planlama Açısından İl Afet Risk Azaltma Planlarının Değerlendirilmesi
}

\author{
Evaluation of Provincial Disaster Risk Reduction Plans in Terms of Urban Planning
}

Serpil GERDAN ${ }^{1}$

\section{ÖZ}

Ülkemizde yaşanan afetler sonrası elde edilen deneyimler son yıllarda başarılı sayllabilecek müdahale ve iyileştirme çalışmalarının yürütülmesine katk1 sağlamış olsa da afet sonrası ortaya çıkan kayıpları azaltmak açısından bu başarı tek başına yeterli değildir. Afet yönetimindeki uluslararası gelişmeler afet kayıplarını ortaya çıkmadan önce azaltabilmenin önemine vurgu yapmaktadır. $\mathrm{Bu}$ da "risk yönetimi odaklı" bir afet yönetiminden söz etmek demektir. Afetlere yönelik uluslararası düzeyde olduğu kadar ulusal düzeyde de benimsenen "afet risk yönetimi” anlayışının merkezi ve yerel düzeyde kapsamlı ve birbiriyle koordineli olarak yürütülmesi afetlere dirençli kentlerin inşası açısında da oldukça önemlidir. Bu çalışmada, Sürdürülebilir Kentleşme ve Mekânsal Gelişme İlkelerinden bir tanesi olan risklerden arınmış, güvenli ve nitelikli yaşam çevrelerinin oluşturulması yaklaşımı ile il Afet ve Acil Durum Yönetim Başkanlığ 1 il müdürlüklerinin koordinasyonunda, 2021 y1l sonuna kadar 81 ilde tamamlanması hedeflenen İl Afet Risk Azaltma Planları kentsel planlama açısından değerlendirilmiştir. Değerlendirme sonuçları, dayanıklı kentlerin inşası için önemli bir yere sahip olan afet risk azaltma planlarının başarıya ulaşmasının zarar azaltma ilkesine dayalı bütüncül bir strateji ile mümkün olacağını göstermektedir.

Anahtar Kelimeler: Afet, Planlama, Hazırlık, Risk Azaltma Planı (IRAP), Kentsel Planlama.

\begin{abstract}
Although the experiences of disaster in our country have contributed to the practice of the intervention and recovery works that can be considered successful in recent years, this success alone is not enough in terms of reducing the losses that occur after the disaster. International developments in disaster management emphasize the importance of reducing disaster losses before they occur. This means talking about a "risk management focused" disaster management. It is also important for the construction of disaster-resilience cities that the understanding of "disaster risk management" adopted at national as well as international level regarding disasters is comprehensive and coordinated at central and local level. In this study, under the coordination of provincial Disaster and Emergency Management Presidency directorates with the approach of creating risk-free, safe and qualified living environments, which is one of the Sustainable Urbanization and Spatial Development Principles, the Provincial Disaster Risk Reduction Plan, which is aimed to be completed in 81 provinces by the end of 2021, Its contribution to the creation of strong cities has been evaluated in terms of urban planning. The results of the evaluation show that the success of disaster risk reduction plans which have an important place for the construction of resilient cities will be possible with an integrated strategy based on the mitigation principle.
\end{abstract}

Keywords: Disaster Planning, Preparedness, Risk Mitigation Plan (IRAP), Urban Planning.

\footnotetext{
${ }^{1}$ Dr. Öğr. Üyesi, Serpil GERDAN, Afet ve Acil Durum Yönetimi, Kocaeli Üniversitesi, İzmit MYO, sgerdan@kocaeli.edu.tr, ORCID: 0000-0001-9126-7808 


\section{GİRIS}

Afetler, toplumun yaşantısını kesintiye uğratan olağandıșı durumları tanımlar. Genellikle kaynağı doğadan gelen ve kriz sonucu doğuran tehlikeler, toplulukların sıcak saatlerde kargaşa yaşadıkları durumlardır. Afet sonucu doğuracak boyuttaki kriz durumları birçok unsurun bir arada faaliyetini zorunlu kılan, karmaşıklığın yüksek düzeyde olduğu durumlardır ve bu nedenle koordinasyon önem kazanmaktadır. ${ }^{1}$ Modernleşme ve sanayileşme gibi faktörlere bağlı olarak kentlerde ekonomik, sosyal ve kültürel sorunlar ortaya çıkmaktadır. Yaşanan bu sorunlar kentleri afetlere karş1 daha kırılgan hale getirmektedir. ${ }^{2}$ Afetler açısından kentlerin dirençli hale dönüştürülmesi, şehrin fiziki planlamasına ve sistemsel işleyişine yönelik kararların afetler gerçekleşmeden önce alınması ile mümkün olabilmektedir. ${ }^{3}$ İstanbul Sismik Riskin Azaltılması ve Acil Durum Hazırlık Projesi (ISMEP), Afete Dirençli Şehir Planlama ve Yapılaşma Rehberinde afetlere dirençli kentler; kriz veya afetlere karşı uyum sağlama yeteneğine sahip yaşam alanları olarak ifade edilmektedir. ${ }^{4}$ Buna bağlı olarak dirençli kentlerin inşası krizin kontrol edilebilir boyutta olmasını sağlamaktan geçmektedir. Deprem gibi yıkıcı sonuçları olan tehlikelerin hasarını arttıran faktörlerin başında jeolojik açıdan sakıncalı alanlara düzensiz ve plansız yapılașma gelmektedir. Planlamadan yoksun strateji ve politikaların geliștirilmesinde israr edildiği sürece de afete dirençli kentlerden bahsetmek mümkün değildir.

Ülkemizin afet ve acil durum yönetim süreci yaşanan 1999 depremlerinden günümüze değişim ve gelişim göstermektedir. "Entegre planlama yaklaşımı ve modüler yapisiyla afet sirasindaki operasyon risklerini en aza indirecek bir sistem olarak 20.12.2013 tarih ve 28871 sayılı Kurul Kararı ile kabul edilen Türkiye Afet Müdahale Planı (TAMP) Türkiye'de yaşanabilecek her tür ve ölçekteki afet ve acil durumlara etkin müdahale için görev alacak, kamu kurumlarl, özel sektör, sivil toplum kuruluşları ve gerçek kişileri kapsamaktadır. ${ }^{5}$ " TAMP genel olarak stratejik, taktik ve operasyonel planlama süreçlerini tanımlamaktadır (Şekil 1).

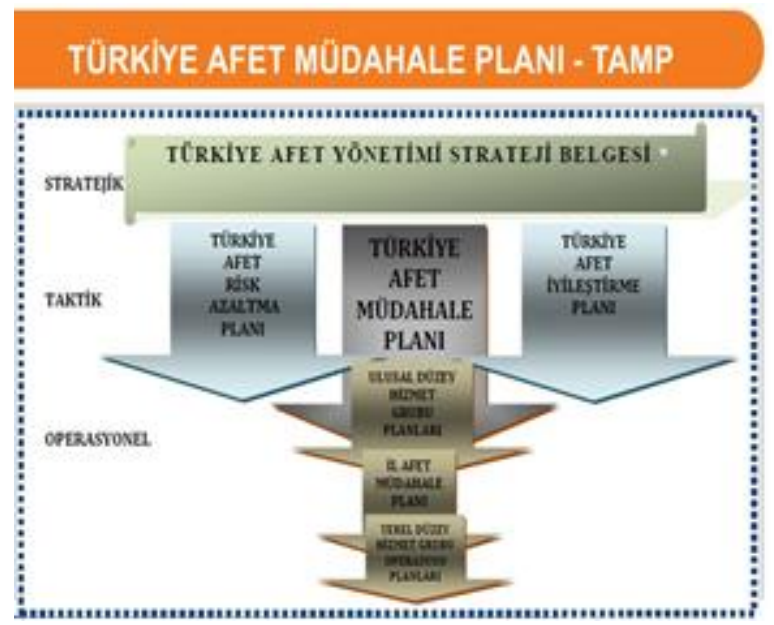

Şekil 1. Türkiye Afet Müdahale Planı

Ancak TAMP'ın müdahalenin organizasyonunu planlaması açısından tek başına iyi bir afet ve acil durum yönetim modelini temsil etmesi mümkün değildir. Gelişmiş ve kabul görmüş bütünleşik bir afet yönetimi, afetler karşısında dirençli veya bir başka deyişle baş etme kapasitesi yüksek bir toplum oluşturmak için kendi tehlikelerini dikkate alan, afet yönetiminin dört evresi olan "zarar azaltma, hazlrlik, müdahale ve iyileştirme" aşamaları ile alınması gereken önlemleri, toplumun tüm güç ve kaynaklarını kullanarak gerçekleştirebilen bir yönetim süreci olarak tanımlanmaktadır. ${ }^{6}$ İște bu noktada ülkemizin afet ve acil durum yönetim yapısının iyi bir risk yönetim modeline ve buna bağlı olarak yerelde tehlike ve risklerin tanımlanarak baş etme kapasitesinin geliştirildiği bir planlama sürecine ihtiyac1 ortaya çıkmaktadır. 15.07.2018 gün 30479 sayıl resmi gazetede yayımlanan

Cumhurbaşkanlığ

Kararnamesinin 52. maddesinin 2. F1kras1 ve 11. Kalkınma Planının 2.4.8 Afet Yönetimi bölümünün 721. Paragrafina dayanarak İl Afet Risk Azaltma Planı (İRAP) çalışmaları 7 şehirde (Adana, Afyon, Kahramanmaraş, Rize, Samsun, Sivas ve Tekirdağ) pilot uygulama ile başlatılmıştır. 
Bu çalışmada, 2021 yılı sonuna kadar 81 ilde tamamlanmas1 hedeflenen İRAP'1n afetlere dirençli kentler oluşturulmasına katkısı kentsel planlama açısından değerlendirilmiştir.

\section{KENTSEL PLANLAMA VE RİSK AZALTMA İLIŞKİSi}

İstenilen hedeflere ulaşmak amacıyla sistemli bir şekilde programların oluşturulması planlama, bir şehrin/kentin daha yaşanabilir bir yer haline getirilmesi amacıyla mevcut kullanım ile olası gelişim kararlarının en yeterli ve gerekli biçimde yönlendirilmesi ise kentsel planlama olarak ifade edilmektedir. Şanlı, (2021)'e göre kentsel planlama, geleceğe yönelik bir tasarıma sahip olmalı, belirli bir hedef ve amaca ulaşmak için yapılmalı ve sistemli bir eylem dizgesi oluşturmalıdır. ${ }^{7} \mathrm{Bu}$ açıdan bakıldığında kentlerin planlı bir şekilde inşa edilmesi sürdürülebilir kalkınmanın öncelikli konularından biri olarak karşımıza çıkmaktadır. Sürdürülebilir bir kent modelinde afetlerin fiziksel, kültürel, ekonomik ve doğal zararlarının azaltılması çalışmaları yer almalıdır. Sanayi ve yoğun nüfusun aktif faylar üzerinde yer aldığ1 ülkemizde maalesef tehlikeler siklıkla afete dönüşmektedir. Kentsel alanlara artan ilgi, iklim değişiklikleri ve doğal yaşam alanlarının tahribatı riskleri daha da arttırmakta ve afetlerde can kayıları ile fiziksel hasarlar meydana gelmektedir. Afetlerin olası olumsuz etkilerinin azaltılması olarak tanımlayabileceğimiz risk yönetimi, planlama ve kapasite geliştirme faaliyetleri günümüzde "afete dirençlilik" olarak ifade edilmektedir. ${ }^{8}$

Risk azaltma çoğu zaman teknik bir konu olarak algilanmakla birlikte sosyolojik, ekonomik, yasal ve yönetimsel süreçleri içerisinde barındıran çok boyutlu bir kavramdır. $\mathrm{Bu}$ nedenle risk azaltma çalışmalarında olası zararları azaltmaya yönelik planlama ve önleme dayalı stratejilerin geliştirilmesi gerekir. Bir kenti tehdit eden tehlikelerin meydana gelme olasılığı ile olası risklerin kontrol altına alınması risk yönetimi ile mümkündür ve riski önlemeye yönelik her bir çalışma tehlikenin afete dönüşmesini engeller. Bir kent için riski azaltmak demek; kentin kamusal ve yaşamsal alanları başta olmak üzere kültürel ve tarihi mirasının, ekonomik ve doğal kaynaklarının maruz kalacağı tehlike ve risklerinin mekânsal olarak değerlendirilmesi demektir. Okay, 2018'e göre bütünleşik kentsel risk değerlendirme ve zarar azaltma yaklaşımı Şekil 2'de şematik olarak verilmiştir. ${ }^{8-12}$

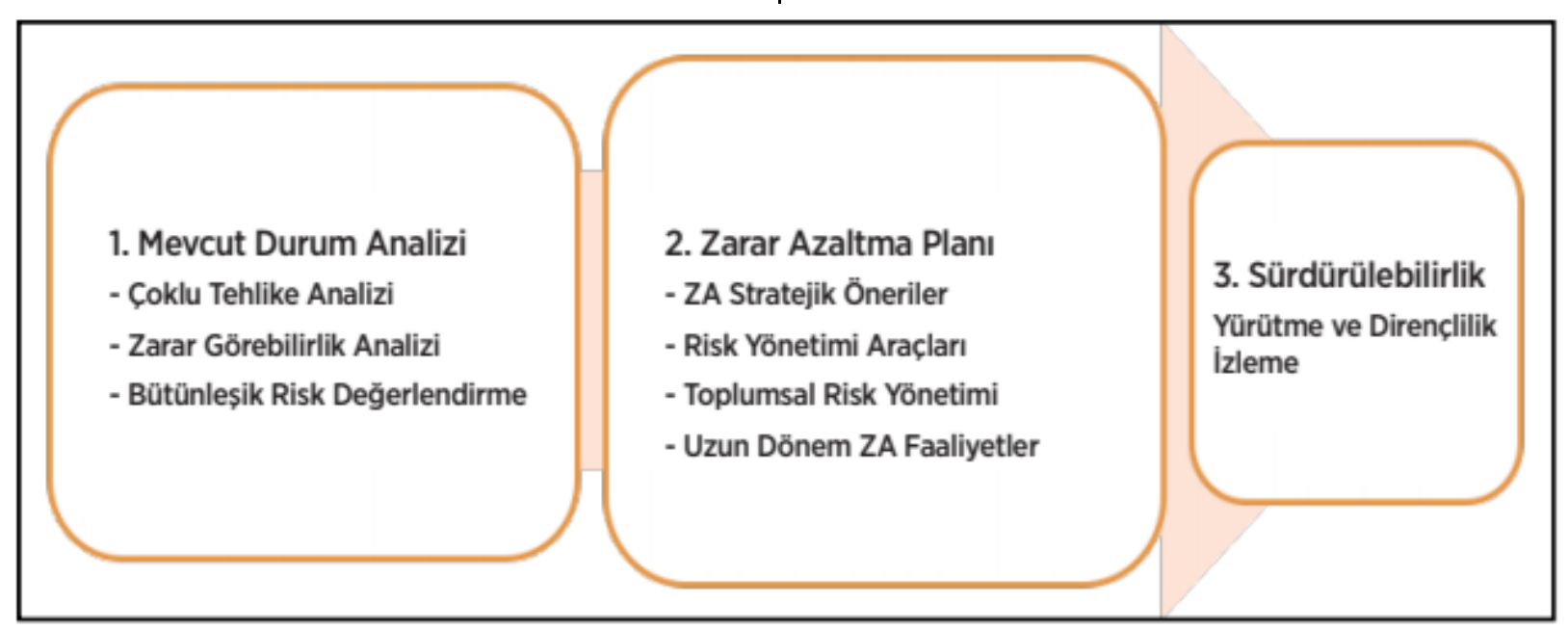

Şekil 2. Bütünleşik Kentsel Risk Değerlendirme ve Zarar Azaltma Yaklaşımı ${ }^{8}$ 
Ersoy, 2021'ye göre planlama geleceğe yönelik geliştirilen bir fikre ve bunun nasıl uygulanacağına ilişkin bir görüşe sahip olmalıdır. Başka bir deyişle, planlama, kuramsal bilginin sistemli bir biçimde eyleme dönüştürülmesidir. ${ }^{13}$ Birçok kaynakta Kentsel Planlama Sürecinin adımları

a) Temel veriler ve alan çalışmaları

b) Araştırma, analiz, sentez ve değerlendirme çalışmaları

c) Gelişme senaryosu, d) Planlama kararları

e) Uygulama, izleme, geri besleme

başlıklarında toplanmıştır. Afet tehlike ve riskleri açısından yüksek olarak nitelenen yerleşmeler veya yapılı kentsel çevre için kentsel risk analizleri araştırma, analiz, sentez ve değerlendirme aşamada yapılır. ${ }^{14}$ Buradan hareketle kentsel planlama ile risk azaltma arasında sıkı bir ilişkinin varlığından söz etmek mümkündür.

\section{ULUSLARARASI SÜREÇLER VE RİSK AZALTMANIN ÖNEMİ}

Acil durumlar ve özellikle doğal afetlerle ilgili mücadele çalışmalarının temelleri 1960'lı y1llara dayanmaktadır. Birleşmiş Milletlerin ekonomik ve sosyal konsey kararlarında sismolojik araştırmalar konusunda uluslararası iş birliğine atıflar yer almaktadır. Birleşmiş Milletlerin son yıllarda afet yönetimi ve afete dirençli kentlerin inşası konularına artan ilgisi nedeniyle birçok uluslararası toplantı düzenlenmiş ve yaşanan tecrübeler 1şı̆̆ında acı kayıpların yaşanmaması adına, bir takım kararlar alınarak ülkelerin bu konuda yapılanması için çabalar başlatılmıştır. ${ }^{15} \mathrm{Bu}$ çabaları, 19901999 yılları arasında afet zararlarının azaltılması teşvik çalışmaları, 1994, Yokohama Stratejisi ve Eylem Planı, 2000 yılında, Afet Zararlarının Azaltılması Uluslararasi Stratejisi (ISDR), 2002 yılında, Johannesburg Eylem Plan1- zarar görebilirlik- risk değerlendirmesi ve 2005 yılında, Hyogo Eylem Planı ve Kobe Konferansı takip etmiştir. ${ }^{16}$

1994 Yokohama Stratejisi ve Eylem Planında; afet zararlarının son yıllarda hızla artması nedeniyle toplulukların özellikle de yoksulların afetlerden çok fazla etkilendiğine vurgu yapılmaktadır. Afetlerin önlenmesi ve zarar azaltma ve hazırlık faaliyetlerinin sürdürebilir kalkınmanın yapı taşları olduğu ülkelerin kalkınma planlarında bunlara yer verilmesinin gerekliliğine vurgu yapılmıştır. $^{16}$

2005-2015 yıllarını kapsayan Hyogo Eylem Planı; risklerin azaltılması konusunda ülkelere rehberlik eden bir yol haritası niteliğini taşıyan uluslar ve toplulukların afet direncinin oluşturulmasını hedefleyen önemli bir dokumandır. ${ }^{16,17}$

Sendai Afet Risk Azaltma Çerçevesi (2015-2030) dokümanı ise Hyogo Çerçeve Eylem Planından elde edilen deneyimler 1şı̆̆ında afetlere dirençli topluluklar oluşturma yolunda aşağıda belirtilmiş olan önceliklerin yerel ulusal, bölgesel ve küresel düzeyde yürütülmesini öngörmektedir.

- Afet riskini anlamak

- Afet risklerinin yönetilebilmesi için afet risk yönetişimini güçlendirmek,

- Dirençlilik için afet risk azaltımına yatırım yapmak,

- Etkin müdahale için afete hazırlı çalışmalarını geliştirmek ve iyileştirmek. $^{17}$

\section{SENDAİ ÇERÇEVE EYLEM PLANI VE İL RISK AZALTMA PLANI (İRAP)}

Sendai Çerçeve Eylem Planı dokümanında "afet riskini anlamak eyleminin gerçekleştirilebilmesi için ulusal ve yerel seviyelerde önem arz eden konular" şu şekilde özetlenmiştir. ${ }^{17}$
- "Verilerin toplanması, analizi, yönetimi ve kullanımının teşvik edilmesi, 
- Afet risklerinin, zarar görebilirlik, kapasite, maruziyet, tehlikenin özellikleri ve bunların ilgili sosyal ve mekansal ölçeklerde, değerlendirilmesi,

- Risk haritaları da dahil olmak üzere konum bazlı afet risk bilgilerinin geliştirilmesi ve güncellenmesi,

- Afet kayıplarinin sistematik olarak değerlendirilmesi, ekonomik, sosyal, sağllkla ilgili, ĕgitsel, çevresel ve kültürel miras üzerindeki etkilerinin anlaşılması,

- Güvenilir veriye gerçek zamanlı erişimin teşvik edilmesi, coğrafi bilgi sistemleri $(C B S)$ ve benzer sistemlerle mekanı ve yerinde bilgiyi kullanmak, ölçüm araçlarını, verilerin toplanmasini, bu verilerin analizini ve yayllmasını gelişstirmek ve iletişim teknolojisindeki yeniliklerden faydalanmak,

- Mevcut ĕgitim ve ögretim mekanizmalarının kullanımı ve benzer yaş gruplarının eğitimi de dahil olmak üzere, deneyimlerin, alınan derslerin, iyi uygulamalartn paylaşılması ve ĕgitim ve öğretim yoluyla tüm kademelerde afet risk azaltmaya yönelik bilgi ve kapasitelerin geliştirilmesini sağlamak. ${ }^{17, "}$

Sendai Çerçeve Eylem Planı dokümanında "afet riskinin yönetilmesi için afet risk yönetişimini güçlendirmek eylemini gerçekleştirebilmek için ulusal ve yerel seviyelerde önem arz eden" konular aşağıdaki gibidir.

- "Afet riskini azaltmaya yönelik çalışmalarl tüm sektörlerde ve sektörler arasında yaygınlaştırmak ve entegre etmek,

- Afet risk oluşumunun önlenmesi ile mevcut risklerin azaltılmasinı sağlayacak ulusal ve yerel afet risk azaltma stratejileri ve planlarını kabul etmek ve bunlart uygulamak;
- Yerel ve ulusal seviyede tanimlanan risklerin üstesinden gelmek üzere, afet risk yönetimi kapasitesinin teknik, finansal ve idari bakımdan değerlendirmesini yapmak;

- Sektörel yasa ve düzenlemelerin arazi kullanımı ve kent planlamasi, yapı güvenliği ile ilgili mevzuat, çevre ve kaynak yönetimi, sağllk ve güvenlik standartları da dahil olmak üzere, güvenliği artırıcı mevcut hükümlerinin üst yönetim seviyelerinde yerine getirilmesini sağlamak ve gereken güncellemeleri, afet risk yönetimine yeterince odaklanarak yapmak üzere, ihtiyaç duyulan mekanizma ve teşviklerin oluşumunu desteklemek;

- Ulusal ve yerel planlart izlemek, bu planlart periyodik olarak değerlendirmek ve kamuya ilerleme raporlart sunmak amaciyla, gerekli durumlarda, mekanizmalar geliştirmek ve güçlendirmek. Yerel ve ulusal afet risk azaltma planlartyla ilgili ilerleme raporlarında, kamu denetimini teşvik etmek ve Parlamenterler ve ilgili diğer görevlilerce gerçekleştirilen çalışmalar da dahil olmak üzere, kurumsal müzakereleri teşvik etmek;

- İlgili yasal çerçevelerde, afet risk yönetimi kuruluşları, süreçleri ve karar verme mekanizmalar dahilinde, topluluk temsilcilerine, gerekli durumlarda, açıça belirlenmiş rol ve görevleri vermek.

- Hükümetler tarafindan koordine edilen ve ulusal ve yerel afet risk azaltma platformlarl da dahil olmak üzere ulusal ve yerel seviyedeki ilgili paydaşlardan oluşan forumlar düzenlemek,

- Işs birliğini sağlamak ve güçlendirmek üzere, gerekli durumlarda, yerel yönetimlere, yerel seviyedeki afet risk yönetiminde sivil toplum, topluluklar, yerel halk ve göçmenlere düzenleyici ve finansal araçlarla yetkiler vermek;

- Parlamenterlerin, ilgili mevzuatı geliştirmek veya mevcut mevzuatı 
gözden geçirmek ve bütçe tahsisi sağlamak suretiyle afet risk azaltma uygulamalarinı desteklemelerini teşvik etmek;

- Özel sektör, sivil toplum, meslek birlikleri, bilim kuruluşları ve Birleşmiş Milletlerin katılımıyla, afet risk yönetimi ile ilgili sertifikalandırma ve ödüllendirme esaslarl gibi kalite standartlarinin geliştirilmesini teşvik etmek;

- Ulusal yasalar ve hukuk sistemleri çerçevesinde, afet risk bölgelerinde, mümkün olan durumlarda, yerleşim alanlarının önlenmesi ve yeniden

\section{Risk Azaltma İçin Sendai Cerçevesi - Öncelikler}

\section{Afet riskini anlamak}

2. Afet riskleri ile baş edebilmek için yönetişimi güçlendirmek

\section{Dirençlilik için risk azaltmaya yatııım yapmak}

4. Etkin müdahale ve iyileştirme için hazırlığı artırmak yerleş̧irilmesi amacıla, uygulanabilir olduğu durumlarda, kamu politikaları geliştirmek. ${ }^{17 \text { ", }}$

Il Afet Risk Azaltma Planı (IRAP) kılavuzunda IRAP; "afetlerin olast etkilerini dikkate alarak; bu etkileri en aza indirmek adına afetler olmadan hayata geçirilmesi gerekenleri süreç dahilinde tarifleyen, sorumlulart ve sorumluluklart tanımlayan sürdürülebilir bir plan" olarak tanımlanmaktadır ${ }^{15}$. İRAP k1lavuzunda İRAP hazırlama yöntemi ve aşamalarının Sendai öncelikleri ile uyumlu olduğu vurgulanmaktadır (Şekil 3).

\section{İAP Hazırlama Yöntemi ve Așamaları Sendai Öncelikleriyle Uyumludur!}

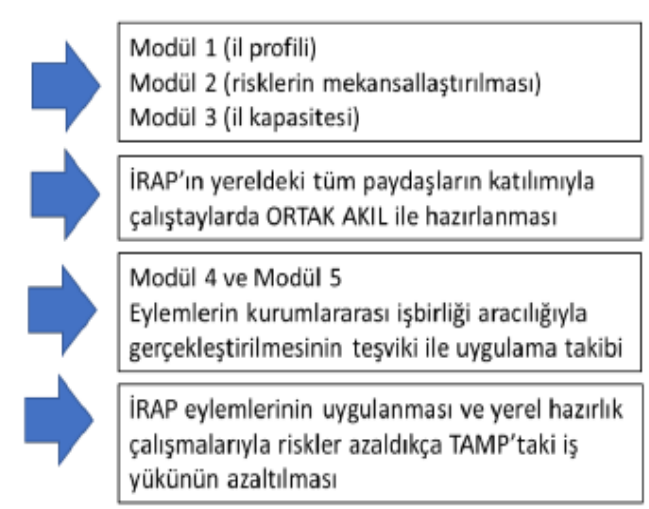

\section{Şekil 3. Sendai Öncelikleri ve İRAP ${ }^{15}$}

İAP risk azaltma planlarının hazırlanma sürecini gösteren bir kılavuz kaynak niteliğindedir ve ancak ilin kendi güç ve kaynakları ile birleştiğinde bir anlam ifade eder. İlin bu kılavuz yardımıyla izlenmesi için gerekli koordinasyonu AFAD il Müdürlükleri sağlamaktadır. İldeki ilgili tüm kurum ve kuruluşların çok paydaşlı iş birliği yaklaşımı ile İl Afet Risk Azaltma Planlarını hazırlamaları gerçek anlamda risklerden sakınmak açısından oldukça önemlidir. Afetlerin olası etkilerinin başa gelmeden değerlendirilmesi ve etkilerinin en aza indirilmesi için izlenecek yol, sorumluluk ve sorumluları tanımlaması açısından İRAP tek bir kurum veya kurulușun değil tüm șehrin planıdır. ${ }^{15}$

\section{SONUÇ VE ÖNERİLER}

Tehlike ve risklerin belirlenerek zarar azaltma çalışmalarının planlamadan yoksun olarak yürütülmesi afetlerle mücadele için tek başına ne yazık ki yeterli değildir. Afetlere karşı dirençli kentlerin oluşturulmasında risk azaltma ve hazırlık çalışmaları, merkez ve yerelde risk azaltma stratejilerine dayalı planlama faaliyetleri ile mümkün olabilir.

Özellikle bölgesel ve il düzeyinde hazırlanacak risk azaltma planları ile il özelinde mevcut durumun analiz edilerek, tehlike ve risk değerlendirme çalışmaları ile bütünleştirilmesi ve muhtemel ve en kötü senaryolarla desteklenmesi gerekir. 
Muhtemel senaryolar ortaya çıkacak acil durumların, en kötü senaryolar ise afetlerin meydana gelmesi durumunda alınmasi gereken aksiyonları tanımlamaları nedeniyle senaryolara dayalı öncelikli uygulamaların belirlenmesi gerekir. İl düzeyinde hazırlanacak risk azaltma planlarının kentin mevcut yapılaşmış, sosyoekonomik ve ekolojik çevreye bağlı zarar görebilirliklerini her açıdan ele alır nitelikte olması da bir diğer önemli konudur. Özellikle sanayinin yoğun ve yerleşim alanı ile içi içe bulunduğu illerde tehlikeli maddelerin varlığı kentin tehlike kaynaklarını oluşturmaktadır. Bunların da ayrı ayrı değerlendirilmesi gerekir. İl Risk Azaltma Planlarında altyapı, ulaşım, kültürel miras, tarihi hassas değerler, ekolojik sistem gibi birçok unsurun bütünleşik olarak ele alınması afetlere dirençli kentlerin inşası için kaçınılmazdır.

Bir diğer dikkat çeken konu ise, il afet risk azaltma planlama sürecinde oluşturulacak yerel afet veri tabanlarının kurumlar arasi entegrasyona uygun yapilanmasinin gerekliliğidir. Risklerin değerlendirilmesi ve planlama faaliyetlerinin kriz yönetiminde başarıya ulaşabilmesi için yerel verilerin bir araya getirilmesi ve değerlendirilmesi gerekir.

Bir diğer dikkat çekici konu ise; yerel yönetim-AFAD-üniversite gibi kurumların risk yönetimi çalışmaları ile ilgili iş birliğinin desteklenmesi ve sürdürülebilirliğinin sağlanmasıdır.

Kentsel planlama sürecinin araştırma ve analiz aşamasında afet ve diğer kentsel risklerin yüksek olduğu alanlar ile yapılı kentsel çevre için risk analizi ve sakınım çalışmaları planlarda esas alınmaktadır. Buna bağlı olarak planlamanın her kademesinde (mekânsal, çevre düzeni, nazım imar, vb.) afet tehlike ve riskleri ile afete maruz riskli alanların belirlenmesi ve olası risklerin azaltılmasına yönelik önlemlerin alınması planlama çalışmalarının önemli bir adımını teşkil etmektedir.

Planlamadan yoksun, hizlı ve denetimsiz kentleşme afetlere bağlı riskleri arttıran ve kentleri tehlikeler karşısında daha kırılgan hale gelmesine neden olan faktörlerden en önemlisidir. Yanlış yer seçimi, yapı stoklarındaki hatalar ve planlamaya dahil teknik tüm hatalar kentin karşı karşıya olduğu tehlikelerinin afete dönüșmesine zemin oluşturan unsurlardır.

Öneri olarak; afet risklerini azaltmak açısından İl Afet Risk Azaltma Planlarının, kentsel planlama içerisinde bütünsel bir strateji ile geliştirilmesi gereklidir.

\section{KAYNAKLAR}

1- Leblebici, Ö. (2014), “Afetlerde Kamu Yönetiminin Rolü ve Toplum Temelli Afet Yönetimine Doğru”. Hitit Üniversitesi Sosyal Bilimler Enstitüsü Dergisi, 7(2), 457-477.

2- Gürsoy, O. (2019), Akıllı Kent Yaklasımı ve Türkiye'deki Büyükşehirler İçin Uygulama İmkânları (Yüksek Lisans Tezi). Hacettepe Üniversitesi Sosyal Bilimler Enstitüsü, Ankara.

3- İPKB. (2018). "Afete Dirençli Şehir Planlama ve Yapılaşma”. Erișim adresi: https://www.ipkb.gov.tr/ekutuphane/afete-direncli-sehir-planlama-veyapilasma_62/(Erişim tarihi: 01.02.2021)

4- İPKB. (2014). "Afete Dirençli Sehir Planlama ve Yapılaşma”. Erişim adresi: https://www.ipkb.gov.tr/wpcontent/uploads/2018/10/ISMEP3_AfeteDirenC3A7liC5 9EehirPlanlama26YapC4B1laC59Fma-1.pdf (Erișim tarihi: 30.12.2020).

5- TAMP. (2013). "Türkiye Afet Müdahale Planı”. Erișim adresi: https://www.afad.gov.tr/kurumlar/afad.gov.tr /2419/files/Afet_Mud_Pl_ResmiG_20122013.pdf (Erișim tarihi: 15.03.2021).
6- AHDER. (2021). "Bütünleşik Afet yönetimi nedir? (2021)". Erișim adresi: https://www.ahder.org/definici ones/butunlesik-afet-yonetimi-nedir (Erişim tarihi: 15.03.2021).

7- Sanlı, T. (2021). "Kentsel Planlamaya Giriș”. Erișim adresi: https://avys.omu.edu.tr/storage/app/public/ tugce.sanli/137040/KENT_103_1-2.pdf. (Erișim tarihi: 01.02.2021).

8- Okay, N. (2018). "Dirençli Kentler İçin Afet Risk Azaltma”. Sehir ve Toplum Dergisi, 10, 117-127

9- Khazai, B, Bendimeard, F, Cardona, O.D, Carreño M-L Barbat A.H, Burton C.G. (2015). "A Guide to Measuring Urban Risk Resilience”. EMI: Philippines.

10- Kadıoğlu, M, Türkoğlu, H, Okay, N, Tezer, A. ve diğ (2011). "Küçükçekmece İlçesinde Afet Risk Yönetimi Kapasitesinin Geliștirilmesi Araștırma Projesi Raporu". İstanbul: Küçükçekmece Belediyesi ve ITÜ̈ Afet Yönetim Merkezi. 
11- Okay, N, Tezer, A, Terzi, F, Akman Pek, N. ve Okumuş G. (2013). "Bayrampaşa İlçesi'nde Afet Risk Yönetimi Kapasitesinin Geliştrilmesi. Afet Risk Yönetiminde Mekansal Planlamanın Entegrasyonu için Risk Analizi ve Zarar Azaltma Önerileri’. İstanbul: Bayrampaşa Belediyesi

12- Tezer A, Okay N, Terzi F. (2015). "Gaziosmanpaşa İlçesi'nde Güvenli Yerleşim için Mekansal Risk Yönetim Kapasitesinin Geliștirilmesi” Proje Raporu. İstanbul: Gaziosmanpaşa Belediyesi.

13- Ersoy, M. (2012). Kentsel Planlama Kuramları. Ankara: İmge Yayınları.

14- URL-1. (2021). "Kentsel Planlamanın Temel Nitelikleri”. Erişim adresi: https://acikders.ankara.edu. tr/pluginfile.php/27326/mod_resource/content/0/NOT\%2 012.pdf (Erişim tarihi: 15.03.2021).

15- İRAP. (2020). "İl Afet Risk Azaltma Planı Hazırlama Kılavuzu”. Erişim adresi: https://irap.afad.gov.tr/ (Erişim tarihi: 01.03.2021).

16- Kuterdem, K, Akın, D, Nurlu, M, (2009). "Afet Zararlarının Azaltılmasında Birleşmiş Milletler Kaynaklı Çalışmalar ve 2005-2015 Yılları Arasında Bir Yol Haritası olarak Hyogo Cerçeve Eylem Planı". Türkiye'nin Afet Yönetimi 11. Yuvarlak Masa Toplantısı. Ankara: ODTÜ,

17- UNISDR. (2015). "Sendai Afet Risk Azaltma Cerçevesi (2015-2030)". Erişim adresi: http://uclgmewa.org/uploads/file/748e86d91ae4409e9188794ddb6 c004d/Sendai_TR.pdf (Erişim tarihi: 05.02.2021). 